\title{
COMPARE AND DISCUSS TO PROMOTE DEEPER LEARNING
}

\author{
Bethany Rittle-Johnson, Jon R. Star, \\ Kelley Durkin, and Abbey Loehr
}

\section{Summary}

Compare and Discuss is an instructional method to promote deeper learning and communicative competence. In the compare phase, students compare two examples, making sense of each and identifying their similarities and differences. In the discuss connections phase, students reflect on key points about the comparison, communicating their ideas with a partner and with the whole class. Evidence-based guidelines for effectively supporting a Compare and Discuss instructional method in the classroom are provided. A supplemental algebra curriculum that incorporates these guidelines for helping students compare and discuss multiple strategies is reviewed to illustrate implementation of the method. Finally, evidence for the effectiveness of the Compare and Discuss instructional method for promoting student maths learning is reviewed.

\section{Compare and Discuss to promote deep learning}

We often learn through comparison. For example, we compare different brands and models of products, we compare one health treatment option to another, and we compare new words, objects and ideas to ones we already know. These comparisons help us recognize what features are important and merit more attention, which can lead to deeper understanding (Gentner, 1983). Indeed, research indicates that comparison promotes learning across a range of topics, including maths, science, and language (Alfieri, Nokes-Malach, \& Schunn, 2013). In this chapter, we focus on using comparison to support mathematics learning. In addition, we briefly consider using comparison to teach other academic subjects. 
In mathematics education, comparison of multiple solution strategies is a recommended instructional method in countries throughout the world (Australian Education Ministers, 2006; Kultusministerkonferenz, 2004; National Council of Teachers of Mathematics, 2014; Singapore Ministry of Education, 2012). Teachers are encouraged to have students share, compare, and discuss multiple strategies for solving a particular problem (e.g., discuss the similarities and differences in the strategies). This recommendation is based on observations that expert teachers in countries such as the United States and Japan sometimes have students compare and discuss multiple strategies for solving problems during mathematics instruction, which is thought to promote their understanding and flexibility (Ball, 1993; Lampert, 1990; Shimizu, 1999).

In contrast, students too often memorize ideas without understanding the ideas or being able to flexibly apply them to new contexts. This is true in many school subjects, including maths, science, and reading. For example, only $13 \%$ of 15-year-olds from around the world could work strategically using broad, well-developed thinking and reasoning skills to solve maths problems. Even in a high-performing country such as Japan, only $24 \%$ of students engaged in this type of thinking and reasoning (OECD, 2016). To improve students' understanding and flexibility, teachers can support comparison of multiple strategies.

\section{Use of comparison in maths textbooks and classrooms}

Textbook analyzes and classroom observations suggest that comparison should be used more often and be better supported in mathematics. First, textbooks provide some opportunities for comparing strategies, but opportunities vary by textbook and are often limited. We examined a variety of textbooks in the United States and Japan and coded how frequently the worked examples (a problem plus a step-by-step strategy for solving it) included more than one strategy for solving the same problem, which is a building block for comparing the strategies. Using textbooks from the United States, we coded the unit on equation solving in ten Algebra 1 textbooks. Multiple strategies were presented for an average of $20 \%$ of worked examples in the unit, with a range from $0 \%$ to $34 \%$ of worked examples. We also coded the nine units on algebra in the 7th to 9 th-grade textbooks that are mostly commonly used in Japan (Tokyo Shoseki and Gakko Tosho). In both textbooks, only $2 \%$ to $3 \%$ of worked examples included multiple strategies for solving the same problem, with no instances in the 9th-grade texts. Japanese mathematics education researchers note that comparing multiple strategies is common in elementary school maths instruction (Shimizu, 1999), so we examined Japanese elementary school textbooks by the same publishers. Presenting multiple strategies for a problem was more common in these textbooks. For example, in the first half of the 5 th-grade textbooks, $12 \%$ to $18 \%$ of examples involved presentation of multiple strategies, with one to two instances 
per unit. Although we did not systematically code for whether comparison was explicitly prompted in the texts, we only noticed prompts for comparison in a few instances.

Second, observations in maths classrooms suggest that teachers, at least in the United States, are limited in the frequency and effectiveness with which they use comparison. In one study in the United States, students were exposed to multiple strategies in $38 \%$ of observed algebra lessons, but teachers or students explicitly compared the strategies in only 9\% of lessons (Star et al., 2015c). In another study in the United States, when asked to design a lesson around a correct and an incorrect strategy for solving an algebra problem, a majority of teachers in training did not plan to explicitly compare the strategies (Schenke \& Richland, 2017). Further, when US teachers do use comparison, the teachers usually do most of the intellectual work, only asking students to assist in elaborating ideas or performing calculations (Richland, Holyoak, \& Stigler, 2004). As a result, it is unclear if students are understanding or learning from the comparisons. In Japan, 8th-grade teachers provide more support for comparison, such as having both examples visible during the comparison and using spatial cues or gestures to help students make comparisons (Richland, Zur, \& Holyoak, 2007).

\section{Description of a Compare and Discuss instructional method}

To help teachers use comparison more frequently and effectively in their instruction, we have developed a Compare and Discuss instructional method. We include discussion because it helps students articulate and reflect on what they have learned and supports learning from comparison (Lampert, 1990; Stein, Engle, Smith, \& Hughes, 2008; Webb et al., 2014). We have developed the method for helping students learn maths, but others have shown that a similar method can be effective for a range of academic subjects, especially science (Alfieri et al., 2013; Gadgil, Nokes-Malach, \& Chi, 2012; Kurtz, Miao, \& Gentner, 2001; Schwartz, Chase, Chin, \& Oppezzo, 2011).

First, students compare two examples, making sense of each and identifying their similarities and differences. In maths, the examples are often two different strategies for solving the same problem. In science, the examples could be two strategies for solving a problem, two real-world examples of the same concept, or a naïve and expert perspective. In reading, the examples could be two different stories, with a focus on comparing the characters or story lines. In history, the examples could be two historical events or people. In all of these domains, the first phase of instruction should focus on students comparing the two examples, identifying similarities and differences. Subsequently, students discuss key points about the comparison, such as when one is better than the other or what the similarities in the examples reveal about a general idea. At the end of the activity, the teacher summarizes the main points of the comparison 


\begin{tabular}{|c|c|}
\hline Compare & Discuss Connections \\
\hline $\begin{array}{l}\text { Prepare to Compare } \\
>\text { What is the problem asking? } \\
>\text { What is happening in the first } \\
\text { method? } \\
>\text { What is happening in the second } \\
\text { method? }\end{array}$ & $\begin{array}{l}\text { Prepare to Discuss (think, pair) } \\
\text { How does this comparison help you } \\
\text { understand this problem? } \\
>\text { How might you apply these methods to a } \\
\text { similar problem? }\end{array}$ \\
\hline \multirow{2}{*}{$\begin{array}{l}\Theta \text { Make Comparisons } \\
\text { What are the similarities and } \\
\text { differences between the two } \\
\text { methods? } \\
\circ \text { Which method is better? } \\
\circ \text { Which method is correct? } \\
\circ \text { Why do both methods } \\
\text { work? } \\
\circ \text { How do the problems } \\
\text { differ? }\end{array}$} & $\begin{array}{l}\text { Discuss Connections (share) } \\
\text { What ideas would you like to share with } \\
\text { the class? }\end{array}$ \\
\hline & $\begin{array}{l}\text { Identify the Big Idea } \\
\text { Can you summarize the Big Idea in your } \\
\text { own words? }\end{array}$ \\
\hline
\end{tabular}

FIGURE 3.1 Overview of a Compare and Discuss instructional method for maths.

and discussion. An overview of a Compare and Discuss instructional method for maths is shown in Figure 3.1.

In maths instruction, this instructional method is useful for various instructional goals, including learning multiple strategies and why and when to use them and for revising incorrect strategies and misconceptions. Other instructional goals, such as consolidating a newly learned strategy, are better met by using other instructional methods, such as problem-solving practice.

\section{Guidelines}

We recommend two phases to instruction: a compare phase and a discuss connections phase. We have developed evidence-based guidelines for each phase (see Table 3.1). In Figures 3.2 and 3.3, we provide examples of materials for the compare phase, and in Figure 3.4, we provide an example of materials for the discuss connections phase, along with a sample student response.

In the Compare Phase, it is important for teachers to:

1. Select two examples that have important similarities and/or differences (Markman \& Gentner, 1993). When examples are too similar or too different, students focus on obvious, unimportant features of the examples, which leads to unproductive discussions. The two examples can be prepared in advance 
TABLE 3.1 Guidelines for effectively supporting Compare and Discuss

Compare phase

1. Select two examples that have important similarities and/or differences.

2. Make the examples visible and clear.

3. Use a variety of comparison types, matched to your instructional goals, such as Which is correct? Which is better? and Why does it work?

4. Present both examples simultaneously, not one at a time.

5. Present examples side by side and use gestures, common language, and other cues to guide attention to important similarities and differences.

6. Prompt students to explain, preferably to a peer.

7. Provide additional support if both examples are unfamiliar to students.

Discuss connections phase

8. Prompt students to reflect on a key point about the comparison (e.g., discuss connections prompts).

9. Use a Think-Pair-Share instructional routine (think on own, pair with another student, discuss with whole class).

10. Summarize the main points of the comparison and discussion.

or created by students. More than two examples can be used, but it may overwhelm students to compare them without considerable support.

2. Make the examples clear and visible. In maths and some science topics, worked examples (a problem and step-by-step strategy for solving it) are very effective examples to help novices learn new procedures and related concepts (Atkinson, Derry, Renkl, \& Wortham, 2000; Sweller \& Cooper, 1985). They clearly lay out solution steps and are commonly included in textbooks, so they are familiar to students. They also provide a visual record of the solution steps. Without visual aids, verbal descriptions of multistep processes or complex ideas can be difficult for students to process because they have to both remember and make sense of the examples (Richland et al., 2007).

3. Use a variety of comparison types, matched to your instructional goals. We primarily use three types to support maths learning.

- Which is better? Examples are two correct strategies for solving the same problem, with the goal of learning when and why one strategy is more efficient or easier than another strategy for a given problem type (see Figure 3.2 for an example). This type of comparison promotes procedural knowledge and flexibility - knowledge of multiple strategies and when to use them (Rittle-Johnson \& Star, 2007).

- Which is correct? Examples are one correct and one incorrect example, with the goal of understanding and avoiding common incorrect ways of thinking (see Figure 3.3 for an example). The examples can be a correct and an incorrect strategy or a naïve and expert perspective. Comparing correct and incorrect strategies supports gains 
Riley and Gloria were asked to graph the equation $3 x-2 y=6$.

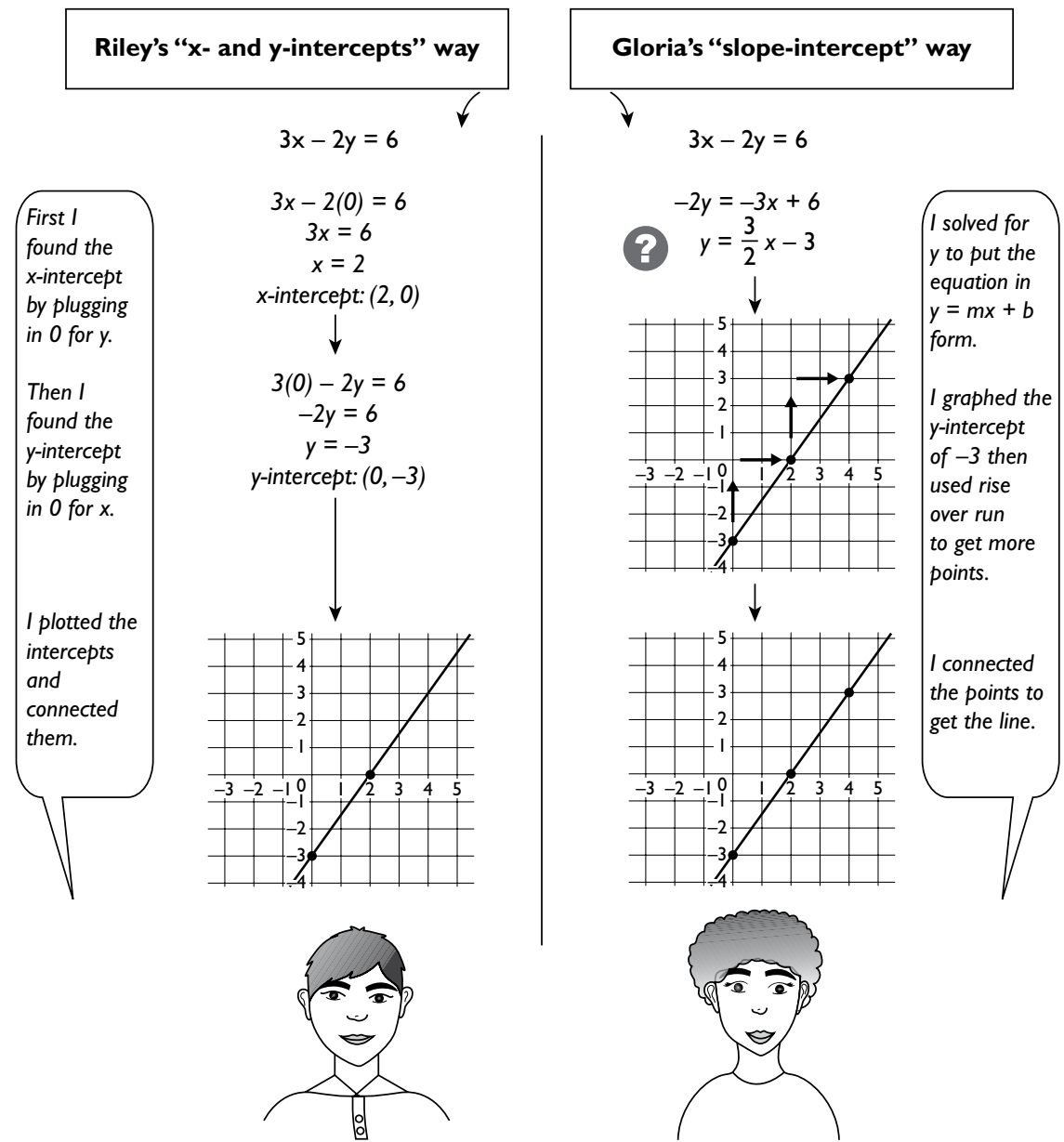

(2) How did Riley graph the line? Why did Gloria solve the equation for $y$ as a first step?

Which method is better?

FIGURE 3.2 Sample Worked Example Pair (WEP) for a Which is better? comparison.

in procedural knowledge, retention of conceptual knowledge, and a reduction in misconceptions (Durkin \& Rittle-Johnson, 2012).

- Why does it work? Examples are also two correct strategies for solving the same problem, but with the goal of illuminating the conceptual rationale in one strategy that is less apparent in the other strategy. 
54 Rittle-Johnson, Star, Durkin, and Loehr

Riley and Gloria were asked if $(-5,6)$ is a solution to the system

$$
\left\{\begin{array}{l}
y=-3 x-9 \\
y=2 x-3
\end{array}\right.
$$

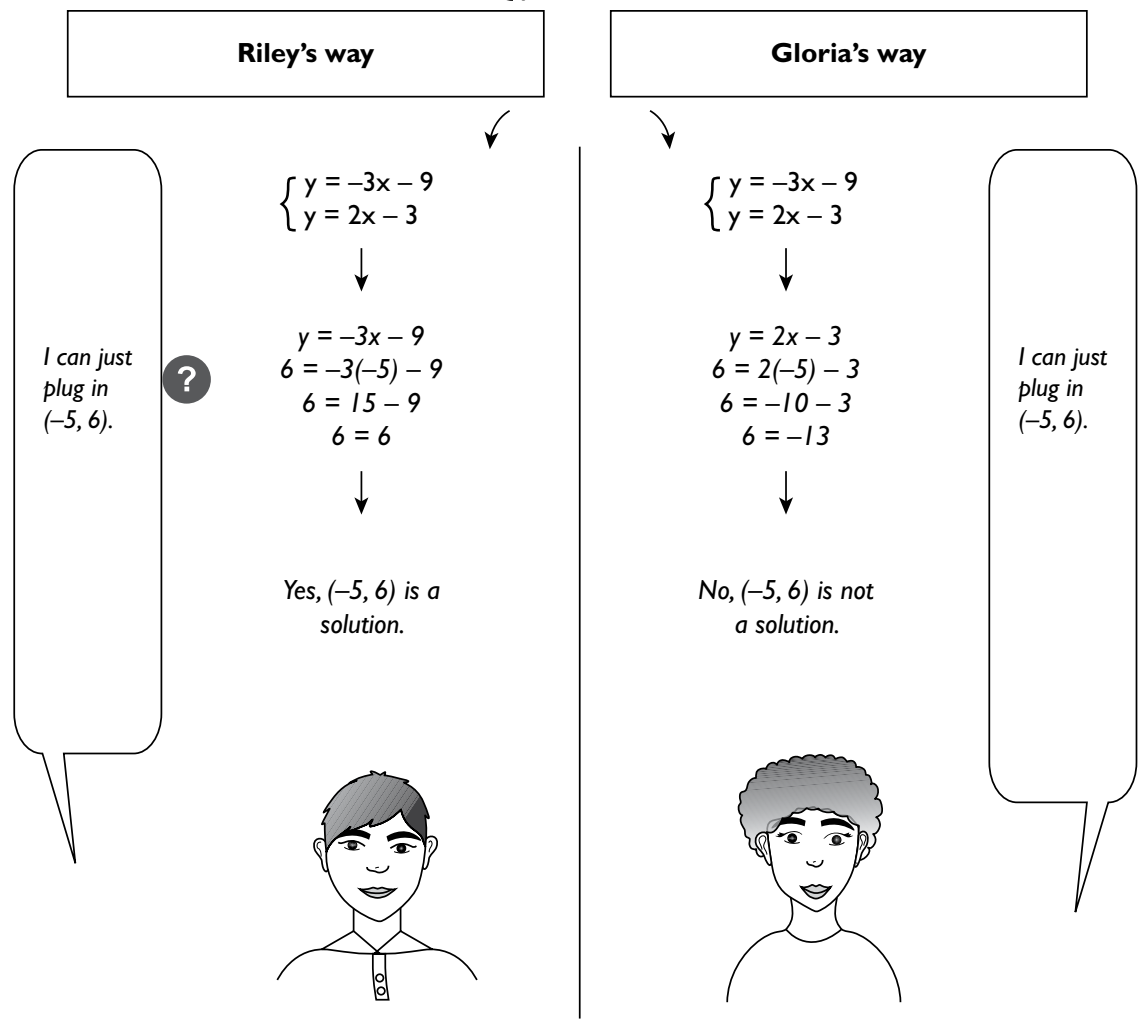

? Does it matter into which equation you plug the point?

What is the same or similar about Riley and Gloria's methods? What is different?

FIGURE 3.3 Sample Worked Example Pair (WEP) for a Which is correct? comparison.

This is in contrast to the Which is better? comparisons, where the goal is to learn when and why one strategy is better for solving particular types of problems. More frequent use of Why does it work? comparisons in the classroom is related to greater conceptual and procedural knowledge (Star et al., 2015c).

4. When engaging in comparison, present both examples simultaneously, not one at a time. Students will make better comparisons because they do not have to 


\section{Discuss Connections}

\section{Can both Riley and Gloria be correct? Can a point be both a solution and not a solution?}

Think, Pair. First, think about the question(s) above independently. Then, get with a partner and discuss your answers. After talking with your partner, what is your answer?

Riley and Gloria are both correct. This is because $(-5,6)$ was only a solution for the equation $y=-3 x-9$. A point can be a solution and not a solution because one point might only be on one line.

(2) Share. After reviewing the worksheet as a class, summarize the answer(s) your class agrees on. Was this different from your original response?

$\rightarrow$ Solution $=2$ lines meet

$\rightarrow$ Can't be no solution + solution at the same time

$\rightarrow$ Solution to equation only (Riley)

$\rightarrow$ Gloria is correct

Big Idea. When your teacher tells you to do so, write what you think is the big idea of this example, in your own words:

The big idea is to show that if the solution isn't an intersection point, it isn't a solution to the system of equations.

FIGURE 3.4 Sample worksheet for Discuss Connections Phase of WEP in Figure 3.3 Sample. student responses included. Typed student explanations in notes.

rely on their memory of one example while comparing (Begolli \& Richland, 2015; Gentner, 1983).

5. Present examples side-by-side and use gestures, common language (e.g., terms such as equivalent, factors, etc.) and other cues (e.g., highlight key parts in the same color) to guide attention to important similarities and differences in the examples. For example, students were more likely to notice that the altitude of a triangle must pass through a vertex if they studied two examples next to each other, one an example of a triangle with an added red line that passed through a vertex and the other an example of the same triangle with an added red line that did not pass through the vertex (Guo \& Pang, 2011). Without supports like these, students may fail to notice important features of the examples that are similar or different, such as whether the proposed line of altitude passes through the vertex (Marton \& Pang, 2006; Namy \& Gentner, 2002; Richland et al., 2007). 
6. Prompt students to explain, preferably to a peer. First, prompt students to explain each example individually to be sure they understand each one. Then, prompt students to compare the two, using both general prompts (e.g., "What are some similarities and differences between the two examples?") and prompts focused on specific aspects of the examples to compare (e.g., "How is their first solution step different?"). Students can do this independently or with a peer, but we recommend students talking with a peer. Generating explanations improves students' comprehension and transfer (Chi, 2000; McEldoon, Durkin, \& Rittle-Johnson, 2013), and talking with peers improves learning and communicative competence (Johnson \& Johnson, 1994; Webb, 1991).

7. Provide additional support if both examples are unfamiliar to students. It is easier to compare an unfamiliar example to a familiar example, such as comparing a new strategy to a strategy students have already learned (Rittle-Johnson, Star, $\&$ Durkin, 2009). Students can learn from comparing two unfamiliar examples, but it requires additional support, such as providing more time for the compare phase and providing carefully crafted explanation prompts that guide students' attention toward key ideas (Rittle-Johnson, Star, \& Durkin, 2012).

In the Discuss Connections Phase, it is important for teachers to:

8. Prompt students to reflect on key points about the comparison (i.e., discuss connections prompts), such as when one strategy is better than the other or what the similarities in the examples reveal about a general idea. Example prompts are: "On a timed test, would you rather use Alex's way or Morgan's way? Why?" and "Even though Alex and Morgan did different first steps, why did they both get the same answer?" Prompts to discuss connections encourage students to think critically about the examples and improve learning from comparison more than they would if they used generic prompts to compare (Catrambone \& Holyoak, 1989; Gentner, Loewenstein, \& Thompson, 2003). In addition, when teachers use more open-ended questions that prompt students to verbalize the main ideas of the lesson, students learn more (Star et al., 2015b).

9. Use a Think-Pair-Share instructional routine to support high-quality discussion, communicative competence, and critical thinking. First, students think on their own for a minute about the discuss connections prompt. Next, each student pairs with another student to discuss the prompt, summarizing their ideas in writing. Students who collaborate with a partner tend to learn more than those who work alone (Johnson \& Johnson, 1994; Webb, 1991). Then, students share their ideas in a whole class discussion. Teachers should call on multiple students to answer the same question and ask students to build on each other's ideas (e.g., "What do you think about Abbey's idea?"). Such classroom discussions promote critical thinking and improve student learning and communicative competence (Lampert, 1990; Stein et al., 2008; Webb et al., 2014).

10. Summarize the main points of the Compare and Discuss connections phases. Direct instruction on the key points supplements learners' comparisons 
and improves learning from comparison (Gick \& Holyoak, 1983; Schwartz \& Bransford, 1998; VanderStoep \& Seifert, 1993). We recommend students to then write a summary of the main points in their own words to be sure they understood and so they can practice communicating their ideas in writing.

\section{Sample curriculum materials: Comparison and Explanation of Multiple Strategies (CEMS)}

For a Compare and Discuss instructional method to deepen student learning, many of the ten guidelines above need to be in place. Given the high demands on teachers to effectively support the Compare and Discuss method, we have created a set of instructional materials using the method that incorporate all of these guidelines. Our project is called Comparison and Explanation of Multiple Strategies (CEMS), and we have developed materials for algebra instruction in the 8th and 9th grades. At the core of the curriculum are worked-example pairs (WEPs) to compare. Each WEP shows the mathematical work and dialogue of two hypothetical students solving an algebra problem. We use the three types of comparison outlined above: Which is correct? Which is better? and Why does it work? As shown in Figures 3.2 and 3.3, two worked examples are presented side by side. To facilitate processing of the examples, we include spatial cues and common language to help students identify similarities and differences. We provide specific explanation prompts to guide student attention to important information. With each WEP, we include a worksheet for students to use during the Discuss phase, a statement of the main takeaway of the WEP to display at the end of the lesson, and a teacher guide with additional explanation prompts, expected student explanations and the main point of the WEP. Our materials cover major algebra topics such as linear equations, functions, systems of linear equations, polynomials and factoring, and quadratic equations. We also designed a 1-week, 35-hour professional development institute to familiarize teachers with the materials and approach. Teachers review and discuss the materials and view videotaped exemplars of other teachers using the materials. In addition, teachers work in groups to plan and teach sample lessons to their peers using the materials, which were implemented and then debriefed by the group. See Newton and Star (2013) for more information on the professional development.

\section{Evidence of effectiveness}

We have conducted extensive research to evaluate the effectiveness of using a comprehensive Compare and Discuss method to deepen algebra knowledge, which includes our CEMS project, overviewed here and reported in detail elsewhere (see also Durkin, Star, \& Rittle-Johnson, 2017; Rittle-Johnson, Star, \& Durkin, 2017; Star, Rittle-Johnson, \& Durkin, 2016). We only report results that were statistically significant. 


\section{Short-term, researcher-led studies}

In our initial research, we redesigned two to three maths lessons on a particular topic. Researchers implemented these lessons during students' mathematics classes (e.g., Rittle-Johnson \& Star, 2007, 2011; Star et al., 2016). In most studies, students in the experimental condition compared two correct strategies, focusing on when each strategy was most appropriate to use (Which is better? comparisons). Other students were randomly assigned (e.g., using the flip of a coin) to the control condition, and they studied the same content sequentially and one at a time, without comparing strategies. This allowed us to isolate the effectiveness of comparison because all students studied multiple strategies. In addition, all students worked with a partner and discussed their ideas. Most studies were with middle-school students learning about equation solving, and one study was with 5 th-grade students learning about computational estimation (e.g., estimating the answer to $34 \times 69$ ).

For example, in Rittle-Johnson and Star's (2007) study, US 7th-grade students $(N=70)$ in pre-algebra classes learned about solving multistep linear equations during three class periods. Students completed a packet of worked examples with their partners, explaining the procedures and answering explanation prompts. Before and after participating in the intervention, students completed an assessment of our three outcome measures. The procedural knowledge measure involved solving algebra equations and the conceptual knowledge measure involved recognizing or explaining algebra concepts, such as like terms indexed. Procedural flexibility was measured in two ways. The first was use of more efficient solution methods when solving equations; the second was knowledge of multiple ways to solve equations, including acceptance of nonstandard ways to solve equations. As predicted, those who compared methods gained greater procedural flexibility. They also acquired greater procedural knowledge. The two groups did not differ in conceptual knowledge in this study.

Across five studies, with hundreds of students, those who compared strategies gained greater procedural flexibility, often gained greater procedural knowledge, and sometimes gained greater conceptual knowledge (for study details, see Rittle-Johnson \& Star, 2007, 2009; Rittle-Johnson et al., 2009, 2012; Star \& Rittle-Johnson, 2009). In one study, comparing strategies was more effective for students who were familiar with one of the strategies than students who were not (Rittle-Johnson et al., 2009). To address this potential limitation of asking students with limited prior knowledge to compare strategies, we gave students more time to learn a smaller amount of material. With these added means of support, comparing strategies immediately supported greater procedural flexibility than delaying exposure to multiple strategies, with or without comparison of the strategies, for all students (Rittle-Johnson et al., 2012). In large part because of our research, Educator's Practice Guides from the US Department of Education identified comparing multiple solution strategies as one of five recommendations for improving mathematical problem solving (Woodward et al., 2012) and 
teaching students to intentionally choose from alternative algebraic strategies when solving problems for improving algebra knowledge (Star et al., 2015a).

\section{Year-long, teacher-led studies}

Given the promise of the Compare and Discuss method to promote maths learning, we created the Comparison and Explanation of Multiple Strategies (CEMS) for Algebra materials and the professional development described in the previous section. We have been refining and evaluating this method in two large studies with teachers.

In the first study, we conducted an initial evaluation of teachers' effective use of our CEMS method (see Star et al., 2015c). Sixty-eight algebra teachers in the United States and their students $(n=1367)$ volunteered to participate and were randomly assigned to implement our CEMS curriculum as a supplement to their regular curriculum (CEMS teachers) or to continue using their existing curriculum and methods ("business as usual" control condition). CEMS teachers were asked to use our materials a few times a week (with about 36 weeks in a school year), deciding which materials to use and when. We supported the compare phase using all six guidelines in Table 3.1, but we provided less support for the discuss connections phase in this initial study (e.g., support for Guideline 8 , but not 9 or 10 , was provided). Teachers completed a log each time they used the materials and submitted a videotape of instruction once a month. CEMS teachers used our materials much less often than requested (i.e., an average of 20 times, for about $4 \%$ of their maths instructional time, with $30 \%$ of teachers using the materials five times or fewer). Coding of the videotapes indicated that teachers implemented the compare phase as intended, but they often did not support sustained class discussion. At the end of the school year, students' algebra knowledge was not higher in classrooms in which our materials were available (based on over 1,600 students). Greater use of our comparison materials was associated with greater student learning, suggesting the approach has promise when used sufficiently often. These results indicated that teachers needed more support in their implementation of our CEMS instructional method.

In a second study, which is ongoing, we are working to better support algebra teachers in their frequent and effective use of CEMS. Figure 3.1 has an overview of the revised method. First, we focus on a smaller number of topics and help teachers plan when they should use all of our materials in conjunction with their existing curriculum. Our guidance includes whether the material is best used at the beginning, middle or end of a lesson on the topic. Second, we provide the Think-Pair-Share instructional routine (Guideline 9) to better promote discussion, critical thinking, and communicative competence. This includes a worksheet for students to record their ideas during each phase (see Figure 3.4). The worksheet promotes use of the routine and provides opportunities for students to communicate ideas in writing. We also provide teachers with additional support 
for the lesson summary, using ideas in Guideline 10 (e.g., see the Big Idea prompt on the bottom of the worksheet in Figure 3.4 asking students to summarize the big idea of the example). Finally, we provide ongoing professional development to the teachers during the school year, providing feedback on lessons they have implemented and how to improve their support for a Compare and Discuss method.

In 2017-2018, nine Algebra I teachers (one 8th grade teacher and eight 9th grade teachers) and their students used our materials. To explore the effectiveness of our teacher professional development for using CEMS, we are coding videos of lessons and comparing the quality of teachers' instruction when teachers were using our materials to when the same teachers were using other curricular materials. Although coding and analysis is ongoing, coding of 33 videos thus far suggests teachers provide higher-quality instruction when using our materials. First, teachers were more likely to support procedural flexibility, such as when one strategy might be more efficient than another, while using our materials. Second, teachers were much more likely to ask "why" and open-ended questions when using our materials than when using other curriculum materials, asking questions such as "Can you generate another problem where Riley's strategy could not be used?" rather than simple questions such as "What is the answer?" Third, students were generating higher-level responses, focused on understanding, such as explaining why an answer was correct or why a particular strategy might have been a good choice. Fourth, discussion among students was more common. Although preliminary, this suggests that using CEMS is improving the quality of their instruction. At the same time, the nine teachers varied substantially in the quality of their instruction with and without our materials. Evaluation of whether using a CEMS approach improves students' maths performance more than typical classroom instruction is in progress.

\section{Discussion}

Compare and Discuss is an effective instructional method to promote deeper learning and communicative competence. In the compare phase, students compare two examples, making sense of each and identifying their similarities and differences. In the discuss connections phase, students reflect on key points about the comparison, such as when one is better than the other or what the similarities in the examples reveal about a general idea. Students communicate these ideas aloud with a partner, with the whole class, and in writing. Ten evidence-based guidelines improve the effectiveness of a Compare and Discuss instructional method, as outlined in Table 3.1.

Theory and evidence for how people learn helps explain why a Compare and Discuss method is effective. Novices have difficulty knowing what features of examples are important, often focusing on surface features (e.g., what letter is used to represent a variable) and because of this, they learn shallow information that they cannot apply to new examples or new contexts (Sweller, van 
Merrienboer, \& Paas, 1998). Comparing examples helps us notice important features of the examples and go beyond surface similarities to more important structural features that can be generalized to new examples and contexts (Gentner, 1983). For example, comparing examples helps students learn that you can add or subtract a variety of quantities from both sides of an equation and maintain equivalence. These strategies for maintaining equivalence can then be used more flexibly in more situations. Further, learning multiple strategies helps us respond appropriately to different situations and can spur invention of additional strategies (Siegler, 1996). To enhance sense-making, generating explanations during learning helps us make inferences, identify errors and integrate ideas (Chi, 2000). Finally, humans are social creatures, and discussing our ideas with others is a critical source of new ideas and helps us refine our own thinking (Tomasello, Carpenter, Call, Behne, \& Moll, 2005).

Discussions help students make their ideas more explicit and better integrated with their prior knowledge, especially when teachers and peers support this process (Lampert, 1990; Stein et al., 2008; Webb et al., 2014). Too often, these core learning processes are not harnessed to support academic learning in schools. A Compare and Discuss method integrates all of these core learning processes to promote academic learning. At the same time, Compare and Discuss requires substantial mental effort of students, who can become overwhelmed by it without adequate support.

Future research needs to continue the development and evaluation of curriculum materials and techniques that can be realistically implemented by teachers to effectively incorporate comparison into their classrooms. This includes identifying and evaluating variations of a Compare and Discuss approach used in different countries, at different grade levels, and for different subjects. For example, Japanese elementary school teachers ask students to share and compare their own solution strategies, not hypothetical students' solution strategies (Shimizu, 1999). The advantages and disadvantages of using students' own strategies need to be identified (e.g., the added demands on teachers to select which strategies to have students present and how to support comparison of them).

We must also identify approaches to professional development and curriculum design that adequately support teachers in infusing Compare and Discuss in their instruction. Our initial effort to provide secondary maths teachers in the United States with materials to promote Compare and Discuss, along with some professional development was not sufficient to improve student learning (Star et al., 2015c). Some teachers struggled to find time to include the materials in their instruction, using the approach very infrequently. Some teachers were not comfortable leading discussions, providing little time for students to generate explanations in response to open-ended questions and to build on each other's ideas (Star et al., 2015b). Our current efforts to provide more support for integrating our comparison materials into the existing curriculum and for leading productive discussions is promising, but additional approaches are needed. 
In conclusion, comparing examples and discussing connections between them can be a powerful instructional method. We need to continue exploring and evaluating ways to most effectively use the method to deepen student learning.

\section{References}

Alfieri, L., Nokes-Malach, T. J., \& Schunn, C. D. (2013). Learning through case comparison: A meta-analytic review. Educational Psychologist, 48, 87-113.

Atkinson, R. K., Derry, S. J., Renkl, A., \& Wortham, D. (2000). Learning from examples: Instructional principles from the worked examples research. Review of Educational Research, $70,181-214$.

Australian Education Ministers. (2006). Statements of learning for mathematics.

Ball, D. L. (1993). With an eye on the mathematical horizon: Dilemmas of teaching elementary school mathematics. The Elementary School Journal, 93, 373-397.

Begolli, K. N., \& Richland, L. E. (2015). Teaching mathematics by comparison: Analog visibility as a double-edged sword. Journal of Educational Psychology, 108, 194-213.

Catrambone, R., \& Holyoak, K. J. (1989). Overcoming contextual limitations on problem-solving transfer. Journal of Experimental Psychology: Learning, Memory, and Cognition, 15, 1147-1156.

Chi, M.T. H. (2000). Self-explaining: The dual processes of generating inference and repairing mental models. In R. Glaser (Ed.), Advances in instructional psychology: Educational design and cognitive science (Vol. 5, pp. 161-238). Mahwah, NJ: Lawrence Erlbaum.

Durkin, K., \& Rittle-Johnson, B. (2012). The effectiveness of using incorrect examples to support learning about decimal magnitude. Learning and Instruction, 22, 206-214.

Durkin, K., Star, J. R., \& Rittle-Johnson, B. (2017). Using comparison of multiple strategies in the mathematics classroom: Lessons learned and next steps. ZDM: The International Journal on Mathematics Education, 49, 585-597.

Gadgil, S., Nokes-Malach,T.J., \& Chi, M.T. H. (2012). Effectiveness of holistic mental model confrontation in driving conceptual change. Learning and Instruction, 22, 47-61.

Gentner, D. (1983). Structure-mapping: A theoretical framework for analogy. Cognitive Science: A Multidisciplinary Journal, 7, 155-170.

Gentner, D., Loewenstein, J., \& Thompson, L. (2003). Learning and transfer: A general role for analogical encoding. Journal of Educational Psychology, 95, 393-405.

Gick, M. L., \& Holyoak, K. J. (1983). Schema induction and analogical transfer. Cognitive Psychology, 15, 1-38.

Guo, J.-p., \& Pang, M. F. (2011). Learning a mathematical concept from comparing examples: The importance of variation and prior knowledge. European Journal of Psychology of Education, 26, 495-525.

Johnson, D. W., \& Johnson, R. T. (1994). Learning together and alone: Cooperative, competitive and individualistic learning (4th ed.). Boston, MA: Allyn and Bacon.

Kultusministerkonferenz. (2004). Bildungsstandards im fach mathematik für den primarbereich [Educational standards in mathematics for primary schools]. Munich, Germany: Luchterhand.

Kurtz, K. J., Miao, C. H., \& Gentner, D. (2001). Learning by analogical bootstrapping. Journal of the Learning Sciences, 10, 417-446.

Lampert, M. (1990). When the problem is not the question and the solution is not the answer: Mathematical knowing and teaching. American Educational Research Journal, 27, 29-63.

Markman, A. B., \& Gentner, D. (1993). Splitting the differences: A structural alignment view of similarity. Journal of Memory and Language, 32, 517-535. 
Marton, F., \& Pang, M. F. (2006). On some necessary conditions of learning. Journal of the Learning Sciences, 15, 193-220.

McEldoon, K. L., Durkin, K. L., \& Rittle-Johnson, B. (2013). Is self-explanation worth the time? A comparison to additional practice. British Journal of Educational Psychology, 83, 615-632.

Namy, L. L., \& Gentner, D. (2002). Making a silk purse out of two sow's ears:Young children's use of comparison in category learning. Journal of Experimental Psychology: General, 131, 5-15.

National Council of Teachers of Mathematics. (2014). Principles to actions: Ensuring mathematical success for all. Reston,VA: National Council of Teachers of Mathematics, Inc.

Newton, K. J., \& Star, J. R. (2013). Exploring the nature and impact of model teaching with worked example pairs. Mathematics Teacher Educator, 2, 86-102.

OECD. (2016). Pisa 2015 results (volume 1): Excellence and equity in education. Paris: OECD Publishing.

Richland, L. E., Holyoak, K. J., \& Stigler, J. W. (2004). Analogy use in eighth-grade mathematics classrooms. Cognition and Instruction, 22,37-60.

Richland, L. E., Zur, O., \& Holyoak, K. J. (2007). Cognitive supports for analogies in the mathematics classroom. Science, 316, 1128-1129.

Rittle-Johnson, B., \& Star, J. R. (2007). Does comparing solution methods facilitate conceptual and procedural knowledge? An experimental study on learning to solve equations. Journal of Educational Psychology, 99, 561-574.

Rittle-Johnson, B., \& Star, J. R. (2009). Compared to what? The effects of different comparisons on conceptual knowledge and procedural flexibility for equation solving. Journal of Educational Psychology, 101, 529-544.

Rittle-Johnson, B., Star, J. R., \& Durkin, K. (2009). The importance of prior knowledge when comparing examples: Influences on conceptual and procedural knowledge of equation solving. Journal of Educational Psychology, 101, 836-852.

Rittle-Johnson, B., \& Star, J. R. (2011). The power of comparison in learning and instruction: Learning outcomes supported by different types of comparisons. In J. P. Mestre \& B. H. Ross (Eds.), Psychology of learning and motivation: Cognition in education (Vol. 55, pp. 199-222). Waltham, MA: Elsevier.

Rittle-Johnson, B., Star, J. R., \& Durkin, K. (2012). Developing procedural flexibility: Are novices prepared to learn from comparing procedures? British Journal of Educational Psychology, 82, 436-455.

Rittle-Johnson, B., Star, J. R., \& Durkin, K. (2017). The power of comparison in mathematics instruction: Experimental evidence from classrooms. In D. C. Geary, D. B. Berch, \& K. M. Koepke (Eds.), Mathematical cognition and learning (Vol.3,pp. 273-296). Waltham, MA: Elsevier.

Schenke, K., \& Richland, L. E. (2017). Preservice teachers' use of contrasting cases in mathematics instruction. Instructional Science, 45, 311-329.

Schwartz, D. L., \& Bransford, J. D. (1998). A time for telling. Cognition and Instruction, 16, $475-522$.

Schwartz, D. L., Chase, C. C., Chin, D. B., \& Oppezzo, M. (2011). Practicing versus inventing with contrasting cases: The effects of telling first on learning and transfer. Journal of Educational Psychology, 103, 759-775.

Shimizu,Y. (1999). Aspects of mathematics teacher education in Japan: Focusing on teachers' roles. Journal of Mathematics Teacher Education, 2, 107-116.

Siegler, R. S. (1996). Emerging minds: The process of change in children's thinking. New York: Oxford University Press.

Singapore Ministry of Education. (2012). Secondary mathematics syllabuses.

Star, J. R., \& Rittle-Johnson, B. (2009). It pays to compare: An experimental study on computational estimation. Journal of Experimental Child Psychology, 101, 408-426. 
Star, J. R., Caronongan, P., Foegen, A., Furgeson, J., Keating, B., Larson, M. R., ... Zbiek, R. M. (2015a). Teaching strategies for improving algebra knowledge in middle and high school students (NCEE 2014-4333). Washington, DC: National Center for Education Evaluation and Regional Assistance (NCEE), Institute of Education Sciences, U.S. Department of Education.

Star, J. R., Newton, K., Pollack, C., Kokka, K., Rittle-Johnson, B., \& Durkin, K. (2015b). Student, teacher, and instructional characteristics related to students' gains in flexibility. Contemporary Educational Psychology, 41, 198-208.

Star, J. R., Pollack, C., Durkin, K., Rittle-Johnson, B., Lynch, K., Newton, K., \& Gogolen, C. (2015c). Learning from comparison in algebra. Contemporary Educational Psychology, 40, 41-54.

Star, J. R., Rittle-Johnson, B., \& Durkin, K. (2016). Comparison and explanation of multiple strategies. Policy Insights from the Behavioral and Brain Sciences, 3, 151-159.

Stein, M. K., Engle, R. A., Smith, M. S., \& Hughes, E. K. (2008). Orchestrating productive mathematical discussions: Five practices for helping teachers move beyond show and tell. Mathematical Thinking and Learning, 10, 313-340.

Sweller, J., \& Cooper, G. A. (1985). The use of worked examples as a substitute for problem solving in learning algebra. Cognition and Instruction, 2, 59-89.

Sweller, J., van Merrienboer, J. J. G., \& Paas, F. G. W. C. (1998). Cognitive architecture and instructional design. Educational Psychology Review, 10, 251-296.

Tomasello, M., Carpenter, M., Call, J., Behne, T., \& Moll, H. (2005). Understanding and sharing intentions: The origins of cultural cognition. Behavioral and Brain Sciences, 28, 675-735.

VanderStoep, S. W., \& Seifert, C. M. (1993). Learning "how" versus learning “when": Improving transfer of problem-solving principles. Journal of the Learning Sciences, 3, 93-111.

Webb, N. M. (1991). Task-related verbal interaction and mathematics learning in small groups. Journal for Research in Mathematics Education, 22, 366-389.

Webb, N. M., Franke, M. L., Ing, M., Wong, J., Fernandez, C. H., Shin, N., \& Turrou, A. C. (2014). Engaging with others' mathematical ideas: Interrelationships among student participation, teachers' instructional practices, and learning. International Journal of Educational Research, 63, 79-93.

Woodward, J., Beckmann, S., Driscoll, M., Franke, M. L., Herzig, P., Jitendra, A. K., ... Ogbuehi, P. (2012). Improving mathematical problem solving in grades 4 to 8: A practice guide. Washington, D.C.: National Center for Education Evaluation and Regional Assistance, Institute of Education Sciences. 